\title{
Implementation of Environmental \\ Considerations in the Innovation \\ Process of Complex Systems: \\ Groupe PSA Case Study
}

\author{
Julien Garcia, Pierre Tonnelier and Sophie Richet
}

\begin{abstract}
Car manufacturer's innovation teams are mainly focusing on decreasing automotive consumption and may lead to risks of transfers of environmental impacts. So, engineers in innovation should be able to evaluate their innovations in a life cycle and multi-criteria perspective. In this paper, Groupe PSA's approach for integrating the environmental dimension during the innovation phase is presented. An eco-design framework of reference has been developed in a collaborative manner by the environment team together with innovation leaders. It tackles both the issues of how to deploy environmental requirements in the innovation process, and how to generate an organizational learning. This methodology is explained through the example of the Stop and Start technology. The validation in the quality procedure is essential to make the approach sustainable.
\end{abstract}

\section{Introduction}

Climate change is the result of an increase in man-made greenhouse gas (GHG) emissions. The main GHG is carbon dioxide $\left(\mathrm{CO}_{2}\right) \cdot \mathrm{CO}_{2}$ is mainly emitted from fossil combustion. The transport sector is highly dependent on fossil fuels: 93\% of the 2013 world transport sector energy supply came from oil products [1]. European Union has tightened European rules on $\mathrm{CO}_{2}$ 's emission of vehicles. By 2020, car manufacturer's fleet will have to emit less than $95 \mathrm{~g} \mathrm{CO}_{2} / \mathrm{km} \mathrm{[2].}$

To reach this goal, car manufacturer's innovation teams are mainly focusing on decreasing automotive consumption. Four strategies can be highlighted: light-weighting, hybridization or electrification of the powertrain, improvements in aerodynamics and rolling resistance, and improvements in energy consumption of the vehicle (air conditioning, radio...). While innovations may contribute to reduce fuel consumption, they also may change the material composition of vehicles and

J. Garcia $(\square) \cdot$ P. Tonnelier · S. Richet

Groupe PSA, Vélizy-Villacoublay, France

e-mail: julien.garcia1@mpsa.com

(C) The Author(s) 2018

E. Benetto et al. (eds.), Designing Sustainable Technologies,

Products and Policies, https://doi.org/10.1007/978-3-319-66981-6_41 
lead to risks of transfers of environmental impacts: as the contribution of the use stage to the impacts is decreasing, the contribution from the manufacturing stage could relatively increase.

In order to prevent transfer of pollution, engineers in innovation should be able to evaluate their innovations in a life cycle and multi-criteria perspective. Environmental evaluation is generally carried out at the end of the product development process and results cannot be used during the design process itself. On the contrary, during innovation, less data on the future vehicle are available, but there are more time and more levers for making changes.

In order to integrate an eco-design approach within a company, tools must be suited to the company, its products, and the corresponding design phase and innovation process. Indeed, both the technical and organizational aspects need to be taken into account simultaneously [3] to ensure (1) the progressive expansion of the environmental field from a technical point of view, and (2) from an organizational point of view, a step by step integration of the environment in all organizational departments to ensure that users are more fully acquainted with the tools and to formalize environmental recommendations that are more accessible.

This article presents Groupe PSA's approach for integrating eco-design method in the innovation process, known as E3PICS (Methodology of an Evolutive integration of the Evaluation of the Environmental Performances of Innovative Complex Sub-systems). E3PICS is based on an eco-design framework of reference that incudes, in particular, a checklist for innovation leaders, and quantitative tools for simulating the effects of the innovations on the future vehicles.

\section{Eco-designing in the Automotive Sector's Innovation Process}

Groupe PSA's desire was to initiate an eco-design method during the innovation phase. For car manufacturers, most of the time, innovations have little impact on the vehicle architecture because of their incremental nature and the fact that such innovations often concern subsystems or components [4]. A set of innovations is generally proposed by the innovation team to the team in charge of the routine design of the vehicle, which Beaume represents as an "innovative feature" flow from the innovation department to the vehicle program department, during the "contextualization phase" [5]. Both structures are completely separated (see Fig. 1).

This study focuses on evaluating innovations during the "contextualization phase", i.e. between Technology Readiness Level (TRL) 5 and TRL 6. This phase aims to validate the connection of an innovation to the vehicle program and contains three milestones: TRL 5: innovation project's commitment; TRL 6: innovation project's connection to a vehicle program; and TRL $51 / 2$ : innovation project's mid-term review. 


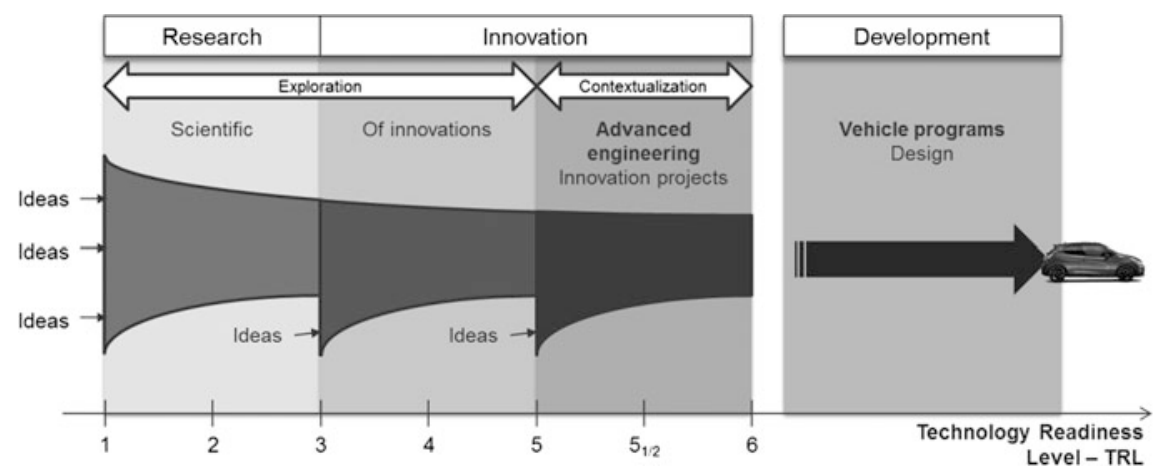

Fig. 1 Groupe PSA's innovation process

The automotive industry has developed several eco-design methods, e.g. Ford's Product Sustainability Index [6], Volvo's Environmental Priority Strategies [7] and Environmental Effect Analysis [8] methods, or Toyota's Eco-Vehicle Assessment System [9]. With the study on the life cycle design of an air intake collector, Keoleian and Kar [10] conclude that evaluating the results of integrating the innovative sub system should be carried out at the future complex system level. But in order to do this, environmental profiles of that complex system are needed. As there is very few data available during the innovation phase, complex systems must be represented by models. Neither the majority of tools developed by car manufacturers, nor the majority of tools available for eco-designing subsystems in the innovation phase [11-13] make it possible to use models to simplify the evaluation of innovative subsystems.

\section{Groupe PSA's Method for Integrating the Environmental Dimension into the Innovation Phase}

The role of Groupe PSA's "Environment" service within the "Materials" department is related to the material composition of the vehicles, and is to control a set of environmental requirements, mostly from regulations. The "Environment" service does not deal with reducing $\mathrm{CO}_{2}$ and pollutants emissions in use. It also hosts an "Eco-design" team dedicated to eco-design process and Life Cycle Assessment (LCA). The requirements driven by this service are already well integrated in the vehicle development programs, but not formalized in the innovation phase. The objective of the "Environment" service is to integrate these requirements during the innovation phase.

E3PICS methodology is based on the definition of an evolving eco-design framework of reference and its use during the innovation phase. It contains all the environmental requirements driven by the car manufacturer's "Environment" 
service. This eco-design framework of reference corresponds to writing the environmental requirements into the product specifications, one of the essential criteria for integrating environment in the design process [14].

E3PICS methodology is shaped by technical and organizational constraints consisting of four steps. The first one concerns the iterative design of the evolving eco-design framework of reference with the "Eco-design" team and with innovation leaders thus generating crossed learning. The second step consists in the "Eco-design" team's support for all innovation leaders so that they systematically use the eco-design framework of reference. The third step is the development of an analytical tool to assess the impact of innovations on vehicles' end-of-life recyclability rate (OSIRIS) [15]; models of vehicles must be created to solve the problem of insufficient data on the complete system during the design phase and to anticipate impacts on the future vehicle. Finally, the fourth step deals with developing a second analytical tool to evaluate the impact of innovations on vehicles' environmental life cycle performance (TEEPI). This tool also requires a method for developing environmental models of vehicles [16].

\section{The Eco-design Framework of Reference}

The eco-design framework of reference constitutes a methodological framework which contains the nine environmental requirements (see Table 1) that the "Eco-design" team wishes to integrate in the innovation process. It is based on a checklist called "Recycling \& Environment checklist" (R\&E checklist) containing requirements with specific deliverables and tools (prescriptive or analytical); a standard mail for the suppliers is also available to retrieve the missing data. Environmental requirements can be divided into two categories:

Table 1 Environmental requirements of Groupe PSA's eco-design framework of reference in the innovation process

\begin{tabular}{l|l}
\hline Nature & Environmental requirement on innovations \\
\hline Intrinsic & Restriction of use of lead, mercury, cadmium, and chromium VI \\
\cline { 2 - 2 } & Ban on the use of chemical substances \\
\cline { 2 - 2 } & Remove the risk of exposure to a chemical in a product \\
\cline { 2 - 2 } & Monitor the use of rare earths \\
\cline { 2 - 2 } & Ability to be pre-treated and/or dismantled at the end-of-life phase \\
\cline { 2 - 2 } & $\begin{array}{l}\text { Ban of component parts which must not be reused in the construction of new } \\
\text { vehicles }\end{array}$ \\
\cline { 2 - 2 } & $\begin{array}{l}\text { Encourage the use of recycled materials, natural organic modified materials and } \\
\text { natural fibres, and biopolymers }\end{array}$ \\
\hline Extrinsic & Evaluate the effects on the vehicle to recyclability and recoverability \\
\cline { 2 - 2 } & Evaluate the effects on the vehicle in terms of environmental impacts \\
\hline
\end{tabular}


(1) The "intrinsic" requirements: An environmental requirement for an innovation is "intrinsic" if it is linked to the function and elements that constitute the innovation; e.g. heavy metal ban, chemical risk elimination, or end-of-life treatment obligations are requirements that are directly related to the innovative element and do not require information on the system that will welcome it.

(2) The "extrinsic" requirements: An environmental requirement for an innovation is called "extrinsic" if it applies to the entire vehicle system; e.g. the ELV Directive requires approval for the recyclability of the vehicle system as a whole and not for the component parts of the vehicle taken separately.

The R\&E checklist aims to evaluate both intrinsic and extrinsic requirements in a "Go/No go" way. It has been co-developed by the eco-design leader and a sample of 11 voluntary innovation leaders. Moreover, for an evolutionary integration of the environmental requirements, the $\mathrm{R} \& \mathrm{E}$ checklist has been integrated in three steps: first, only intrinsic requirements; second, addition of the recyclability effect evaluation; and third, addition of the environmental impact evaluation. The co-development and the evolutionary integration have led to two major results:

(1) Beginning of a cross learning process: the "Eco-design" team has learned on innovation process, and innovation leaders have learned on environmental requirements.

(2) Systematic use of the $R \& E$ checklist in the innovation process: The $R \& E$ checklist was submitted to the department in charge of the quality in innovation; it has validated the inclusion in the milestone reviews of a paragraph relating to the environmental requirements requiring an approval from the "Eco-design" team. To obtain this approval and to validate the TRL 5, TRL 51/2, and TRL 6 milestones, the paragraph prescribes the completion of the R\&E checklist by the innovation pilots.

\section{Focus on the Environmental Impact Evaluation Requirement}

Both extrinsic requirements need an analytic evaluation tool to propagate the effects of the innovation to the complete future vehicle. Here is presented TEEPI, a tool for evaluating the environmental performance of innovations.

\subsection{TEEPI Operation}

TEEPI has been developed to evaluate the impact of innovations on vehicles' environmental life cycle performance. This tool also requires a method for developing environmental models of vehicles. Indeed, in a previous paper [16] we 
developed a method to create Evolving Models for the Environmental Evaluation of Complex Systems (EMEECS). EMEECS are supported by Hierarchical Agglomerative Clustering (HAC) [17] for processing vehicles' available LCA results followed by an algorithm for creating optimal clusters relative to a fixed uncertainty threshold.

For building EMEECS, available results of previous LCA are collected over a fixed number of life cycle stages and of environmental indicators. The life cycle stages are:

- Manufacturing: including raw materials extraction, manufacturing processes; excluding upstream and downstream logistics; the assembly plants are considered separately;

- Use: including well-to-wheels fuel consumption, tank-to-wheels emissions of $\mathrm{CO}_{2}$ and pollutants ( $\left.\mathrm{CO}, \mathrm{NOx}, \mathrm{HC}\right)$, maintenance;

- End of life: no credit has been taken into account because of recycled material provision.

Four environmental indicators are included in the study. These indicators are generally used by car manufacturers to communicate, or by scientific papers in the automotive sector. They are calculated using the CML 2001 method:

- Global warming potential, GWP, [kg CO 2 -Equivalent];

- Eutrophication potential, EP, [kg Phosphate-Equivalent];

- Photochemical ozone creation potential, POCP, [kg Ethen-Equivalent];

- Abiotic depletion potential, ADP, [kg Sb-Equivalent].

LCAs are processed with a HAC in order to classify the vehicles' environmental indicators values in dendrograms per life cycle stage and per environmental impact category. HAC is chosen because it is one of the most common methods to make clusters from a statistical population. As a result, each dendrogram is processed for extracting the "optimal" clusters, i.e. clusters whose error relative to real values of vehicles within the cluster is inferior to a fixed threshold. Each cluster has a value (the average value of vehicles' environmental indicators that form the cluster) and an uncertainty (the standard deviation of those same values). The EMEECS are environmental impact archetypes, calculated on several life cycle stages, of complex system clusters, i.e. the user of the proposed method would directly use the environmental impacts values of the initial and innovative solutions, and of the global system.

\subsection{Case Studies: Micro-Hybridization Systems}

TEEPI was tested on two micro-hybridization systems: fuel-electricity (Inno_1) and fuel-compressed air (Inno_2). The reduction in fuel consumption is achieved through supplying energy, complementary to traditional fossil energy to move the 
Table 2 EMEECS characteristics of Inno_1 and Inno_2

\begin{tabular}{l|l|l}
\hline EMEECS & Inno_1 & Inno_2 \\
\hline Type & B & B \\
\hline Shape & Sedan & Sedan \\
\hline Finish & Average & Average \\
\hline Gearbox & Manual & Manual \\
\hline Fuel & Diesel & Gasoline \\
\hline Consumption $[L / 100 \mathrm{~km}]$ & 3,8 & 4,5 \\
\hline Assembly plant & AP_A & AP_A \\
\hline
\end{tabular}

car. Both micro-hybrid systems require extra parts to be added to the vehicle. For innovative solution Inno_1, the hybridization requires a lead battery heavier than the normal one, an electronically-controlled gearbox instead of the manual gearbox, a reversible starter-alternator ensuring the Stop and Start function, and an ultracapacitor to supply the required power. The innovative solution is $42 \%$ heavier than the initial solution; nevertheless, a diesel consumption reduction of $11 \%$ was measured on the NEDC homologation test. Concerning innovative solution Inno_2, the gearbox and the powertrain adaptation are largely affected, an ultracapacitor is also added, while the lead battery mass is reduced. The innovation solution is $151 \%$ heavier than the initial solution; nevertheless, a 35\% reduction in gasoline consumption was measured on the NEDC homologation test. Table 2 is a synthesis of the vehicle characteristics for selecting the EMEECS, which are available to the "Eco-design" team during the innovation phase. On Fig. 2, TEEPI results are compared to the reference LCAs of Inno_1 and Inno_2.

We observe that the signs of the growth rates given by TEEPI are the same as those of the reference LCAs. Concerning the values of growth rates, the maximum

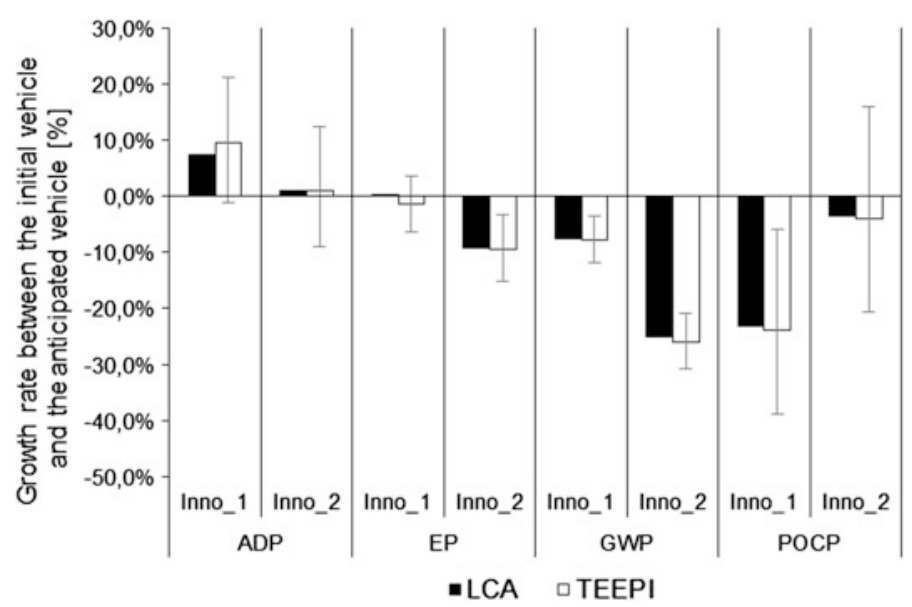

Fig. 2 Comparison between the results from TEEPI and the results from reference LCA for micro-hybrid systems Inno_1 and Inno_2 
error of TEEPI on the five innovations compared to reference LCAs is $2.1 \%$; this is obtained for the ADP indicator of Inno_2. We can also notice that the uncertainties of POCP are significantly higher than those of the other indicators. The length of uncertainty interval of the POCP indicator is directly linked to the use phase, for which the POCP depends on the emissions of three pollutants (carbon monoxide, nitrogen oxides, and hydrocarbons). These emissions vary randomly from one vehicle to another and from one powertrain to another.

\section{Conclusion}

E3PICS methodology has led to a successful integration of the "Environment" service's requirements in the innovation phase. Through the validation of the eco-design framework of reference in the quality procedures, the R\&E checklist is systematically used for all innovations from TRL 5 to TRL 6.

TEEPI was developed to take into account one of the "Environment" service's requirements of the eco-design framework of reference. Validating the eco-design framework of reference within the innovation process implies systematic use of TEEPI for the environmental evaluation of innovations that are selected according to three criteria defined by the eco-design leader: mass of the innovative solution, material change between initial and innovative solution and impact on vehicle fuel consumption.

TEEPI was not designed for generating eco-designed innovative concepts; therefore, it would be relevant to link this tool to a decision-making design tool such as those using the problem resolution by constraint satisfaction algorithm [18].

From an organizational point of view, TEEPI has been approved for being used during the innovation process; it is currently used by the LCA expert. Each innovation is saved in a database that could be used as a case-base in order to use knowledge management systems and generate good practices in eco-designing products. Lastly, to make it easier for innovation leaders to take the environmental dimension into account, they could use a version of TEEPI integrated into a company's intranet platform administrated by the LCA expert. This would help innovation leaders to simulate several innovation options directly. However, a necessary condition would be that innovation leaders have a good knowledge of life cycle issues. The current version of TEEPI is the learning vector of this knowledge.

\section{References}

1. International Energy Agency, Key World Energy Statistics 2015, 2015.

2. European Parliament Council, Regulation No. 443/2009 of the European Parliament and of the Council of 23 April 2009 setting emission performance standards for new passenger cars 
as part of the Community's integrated approach to reduce $\mathrm{CO}_{2}$ emissions from light-duty vehicles, 2009.

3. Johansson G, Greif A, Fleischer G, Managing the design/environment interface: studies of integration mechanisms, International Journal of Production Research, Vol. 45, No. 18-19, 2007, pp. 4041-4055.

4. Oltra V, Saint Jean M, Sectoral systems of environmental innovation: An application to the French automotive industry, Technological Forecasting and Social Change, Vol. 76, No. 4, 2009, pp. 567-583.

5. Beaume R, Maniak R, Midler C, Crossing innovation and product projects management: A comparative analysis in the automotive industry, International Journal of Project Management, Vol. 27, No. 2, 2009, pp. 166-174.

6. Schmidt W-P, Life Cycle Tools within Ford of Europe's Product Sustainability Index. Case Study Ford S-MAX \& Ford Galaxy (8 pp), The International Journal of Life Cycle Assessment, Vol. 11, No. 5, 2006, pp. 315-322.

7. Karlsson R, Steen B, Wendel A, EPS as a Life Cycle oriented System Assessment Tool to Facilitate Industrial Learning about Relations to the Environment, The 15th International Conference of the System Dynamics Society, Istanbul, Turkey, 1997, pp. 61-68.

8. Tingström J, Karlsson R, The relationship between environmental analyses and the dialogue process in product development, Journal of Cleaner Production, Vol. 14, No. 15-16, 2006, pp. 1409-1419.

9. Nakano K, Hirao M, Collaborative activity with business partners for improvement of product environmental performance using LCA, Journal of Cleaner Production, Vol. 19, No. 11, 2011, pp. 1189-1197.

10. Keoleian G.A, Kar K, Elucidating complex design and management trade-offs through life cycle design: air intake manifold demonstration project, Journal of Cleaner Production, Vol. 11, No. 1, 2003, pp. 61-77.

11. Bocken N.M.P, Allwood J.M, Willey A.R, King J.M.H, Development of an eco-ideation tool to identify stepwise greenhouse gas emissions reduction options for consumer goods, Journal of Cleaner Production, Vol. 19, No. 12, 2011, pp. 1279-1287.

12. Gasafi E, Weil M, Approach and application of life cycle screening in early phases of process design: case study of supercritical water gasification, Journal of Cleaner Production, Vol. 19, No. 14, 2011, pp. 1590-1600.

13. Poudelet V, Chayer J-A, Margni M, Pellerin R, Samson R, A process-based approach to operationalize life cycle assessment through the development of an eco-design decision-support system, Journal of Cleaner Production, Vol. 33, 2012, pp. 192-201.

14. Hatcher G.D, Ijomah W.L, Windmill J.F.C, Integrating design for remanufacture into the design process: the operational factors, Journal of Cleaner Production, Vol. 39, 2013, pp. 200-208.

15. Garcia J, Millet D, Tonnelier P, A tool to evaluate the impacts of an innovation on a product's recyclability rate by adopting a modular approach: automotive sector application, International Journal of Vehicle Design, Vol. 67, No. 2, 2015, pp. 178-204.

16. Garcia J, Millet D, Tonnelier P, Construction of evolving models for the environmental evaluation of innovative sub-systems based on a hierarchical agglomerative clustering, International Journal of Sustainable Engineering, Vol. 8, No. 6, 2015, pp. 386-404.

17. Hastie T, Tibshirani R, Friedman J.J.H, The elements of statistical learning, Springer New York, 2001.

18. Tchertchian N, Yvars P-A, Millet D, Benefits and limits of a Constraint Satisfaction Problem/ Life Cycle Assessment approach for the ecodesign of complex systems: a case applied to a hybrid passenger ferry, Journal of Cleaner Production, Vol. 42, 2013, pp. 1-18. 
Open Access This chapter is licensed under the terms of the Creative Commons Attribution 4.0 International License (http://creativecommons.org/licenses/by/4.0/), which permits use, sharing, adaptation, distribution and reproduction in any medium or format, as long as you give appropriate credit to the original author(s) and the source, provide a link to the Creative Commons license and indicate if changes were made.

The images or other third party material in this chapter are included in the chapter's Creative Commons license, unless indicated otherwise in a credit line to the material. If material is not included in the chapter's Creative Commons license and your intended use is not permitted by statutory regulation or exceeds the permitted use, you will need to obtain permission directly from the copyright holder.

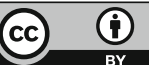

